\title{
Feminism against Beauty Standards in South Korea: Force Creates Resistance
}

\author{
Syamimi Waznah Hamdon ${ }^{1 *}$, Fitriani Bintang Timur ${ }^{2}$
}

${ }^{1}$ Centre for General Studies and Co-curricular,

Universiti Tun Hussein Onn Malaysia, Johor, MALAYSIA

${ }^{2}$ Department of International Relations,

Universitas Indonesia, Depok, INDONESIA

*Corresponding Author

DOI: https://doi.org/10.30880/jts.2021.12.02.008

Received 23 August 2020; Accepted 24 December 2020; Available online 24 January 2021

\begin{abstract}
This article explores about the resistance that women in South Korean made in regards to the unrealistic beauty standards that is projected for the Korean women in order for the to get a place in social involvement. Women in South Korea are marginalized, and although the population in women in South Korea is $49.93 \%$ in 2019 which is a balanced number for both female and male, but their voices remain as minority within the society involvement. In regards, they are often isolated from important social and professional networks and subjected to the negative stereotyping of becoming a feminist. Women in Korea are ought to have the attributes of beauty standards or else, society would judge them and this is a sign that women are trapped with these kind of projection thus it become a barrier for them to grow themselves. Why beauty standards matter among women in South Korea and how global feminism influence women in South Korea to create a resistance against rigid beauty standards in South Korea? To explore this question, this study used qualitative method with phenomenology approach. Drawing on the concept of transnational feminism as well as feminist standpoint theory, this study expected to find the actions taken by the women in South Korea to oppress the idea of objectifying women into certain characteristic of beauty and the oppression of "pretty priviledge".
\end{abstract}

Keywords: Feminism, transnational feminist, beauty standards, objectifying

\section{Introduction}

The word of beauty is owned by everything even though it is non-living things. It can be used to express a stunning view, colour, attitude, and even the artworks. However, days by days, this word's usage has become more narrow as people start to focus "beauty" as a person who meets certain criteria. Sadly, according to the popular trends that made all beauty people look alike, society defines beauty as similar attributes.

Even sadder is they value the concept of beauty based only physical appearances despite treasuring a human's personality. This mentality is very much suitable to be explained as objectifying human whereby a person is being described by its outside instead of his or her traits. Men and women can experience this kind of culture, but according to the ResearchGate statistic, women are $47 \%$ more objectified than men (Galdi \& Silvia, 2014). Women tend to be unconscious that they are being objectified by society because they think they are being lied to society's stereotype. Therefore, they have to follow the flow of the trend that shapes a woman's beauty standards to survive in living.

These events are hidden everywhere, and in this paper, these events would reveal the stereotype of beauty standards in South Korea in the perspective of feminism understandings. In South Korea, individuals have to be momjjang or ŏljjang, which means having perfect bodies or faces to succeed in life (Park, 2018). South Korea is well known as "plastic surgery capital" of the world, as it has the highest number of cosmetic procedures per capita worldwide. It explains why there are more than 600 plastic surgery clinics in Seoul alone (Alexa, 2019). It is estimated 
by the International Society of Aesthetic Plastic Surgery that around 650,000 cosmetic procedures were done in South Korea in 2011. In South Korea, the body and the face are the keys to social status.

\section{Literature Review}

The idea of feminism has been discussed since 1949 as Simone de Beauvoir, in her book of The Second Sex, emphasises how women become the other and inferior to men in terms of biological facts, psychology, and social traits and myths about women. In the biological perspective, she sees the enslavement of women towards her passive role in heterosexual intercourse relative to man's active role. Women then alienated by carrying the external part of the men's sperm. She becomes, in part, another than herself. Society has selected women to play the role of the other (Beauvoir, 2011).

She also criticised Marxism, which classified women to a creature that do the house chores and taking care of the child. In contrast, men go outside and do tasks like hunting and fighting, making women proletariat and men as bourgeois. Simone de Beauvoir also mentioned that society's myth of women betrays women's fundamental value and worth. Men claimed that women who are willing to sacrifice for him, stand all the time by his side and give up their lives for him are the most idealistic women. Women could not object that because men have the power to control her. To Beauvoir, men pay no attention to women's cries, pains, and sorrow, making them naturally bear all the misfortune. Besides that, she also sees that marriage is a form of slavery (Tong \& Botts, 2017).

However, the idea of the existentialist feminism of Simone de Beauvoir is then argued by the post-modern feminism as what Elshtain stated that de Beauvoir's anxiety about the female body shows her insecurity and strong independent woman in the eyes of men. De Beauvoir also feels distrust of the female body, and she also celebrating men norms as active and superior (The Ethics of Ambiguity, 2018). Thus, making the society to be raised in that mentality forever. She should come out with points that will make women look greater than men or focus on women's ability to change the world instead of degrading women's status. Her points could breach the concept of nothingness if men apply it to their situation, and men can also employ the being-for-itself mindset without bad- faith of the de Beauvoir ideas of women as the second sex. Therefore, her points slipped off slightly and seemed delusional because not all women experience what she mentioned in her book. Some women are willing to sacrifice and love to be a mother without asking for a return because mothers love their children unconditionally, thus making her happy. Feminist is existed to get their opportunity to be politically and economically involved in society and make the personal experience as an argument would only make that woman an emotional creature. The post-modern feminist is now mature enough to differentiate between emotion and facts, unlike existentialist feminist.

Meanwhile, in South Korea, women face the patriarchy system and what is worse is that pretty privilege is given to the women who follow the beauty standards. According to Seung Chul Rhee (2014), Teuim Aesthetic Cosmetic Surgery Clinic and Damsoyu Hospital, Seoul, plastic surgeons should observe and analyse the perceptions of beauty and interpret it according to the up to date trends in aesthetic preferences to make sure they meet the expectations of the public in order to satisfy their clients' demand. Meanwhile, Valerie Gelezeau (2015) suggested that if a person is not "mi-in" which is a lovely and pretty person, you are belong to a miyŏng hawui kyegŭp means that a cosmetic underprivileged or underclass and your social status is also in danger. It is forthright to mention that the physical look of the body and the face are crucial factors in the Republic of Korea's social life.

Some observers decide specific criteria of beauty as "hybrid", but within the Asian context, they are thought to be from Korean origin. These well-defined criteria are notably coded for girls, who have a face that's as regular and symmetrical, with a "narrower lower face, large eyes, tiny mouth and a fine, oval jawline" (Elfving-Hwang, 2013). As for the body, the norm is long slender legs.

\section{Problem Statement}

South Korea faces with the critical issue of gender inequality in certain area and contexts. South Korea ranks at 108 out of 153 countries regarding gender inequality (World Economic Forum, 2019). As an advance-technology nation, it is seen a low rank, and they still preserve the conservative mindset of Confucian even though the era of modernity takes place currently. The index also showed that categories like "economic participation and opportunity" and "political empowerment" in South Korea among women were also at a lower rank.

Feminism idea in South Korea is still not fully accepted as the sexism is still a pressing issue in any aspect of South Korean life. The opportunity for women in South Korea to be involved in certain areas like politics and economics is very little. It is becoming worse when women are projected into unrealistic beauty standards to get that little opportunity, and it is the key to social status. Therefore, there is much plastic surgery businesses going on in South Korea (Alexa, 2019). Do women need to change their physical appearance to get fit into society? Many Korean women are against with this idea, so they rebelled it even though Korean society has a different perspective of viewing feminism. 


\section{Research Questions}

1. Why beauty standards matter among women in South Korea?

2. How global feminism influence women in South Korea to create resistance against rigid beauty standards in South Korea?

\section{Theoretical Framework 5.1 Feminist Standpoint}

Standpoint feminism assumes that the state is a set of patriarchal practices that support women's structural losses. This thought criticised the patriarchal state, which originated from the history of the separation of government and private layers, giving rise to men's placement as leaders. Besides, standpoint feminists argue that this understanding should focus on marginalised and disadvantaged women, not just seen through the system. According to Hennessy, this theory has challenged the assumption that being a woman can understand feminists as a whole. Some women are under unconsciousness that they have been portrayed as objects because not all women experience the same thing. Thus, women who are concerned and conscious about the discrimination upon women need to empower other women.

\subsection{Marxism}

Marxism theory explains how work can give impacts on someone's life. Social class has a direct influence on one's life experiences and life chances. This theory is suitable for this research because it includes how beauty standards impact the workplace. People who meet the traits of that 'beauty' has special treatment from employers and co-workers (Tay,2018). This different social class leads to gender inequality in the workplace as women get paid not because of their ability or performance but because of 'beauty'. Next, this will discriminate the lady who does not follow the 'ideal beauty standard' because pretty girls dominate and capitalise in the society.

\subsection{Transnational Feminism}

Transnational feminism refers to a recent feminist paradigm and will usually come with the activist movement to oppress and symbolise women's rejection towards inequality of gender. The activist practices are usually involved with the economic process, and the capitalist economy affects individuals across nations, races, genders, classes, and sexualities. This movement asks to critique the ideologies of ancient white, classist, western models of feminist practices from the associate intersectional approach and how they connect with labour, theoretical applications, and analytical observe on a government scale.

Global feminism believes that the term "international" emphasises on nation-states as distinct entities, which "global" speaks to liberal feminist theories on "global sisterhood" concept to defend together the rights of all women around the world especially Third World country. The transnational feminist is concerned in activist movements across the world so that everyone can know about the role of gender, state, race, class, and sex in critiquing and resisting patriarchic society structures; an alternative for women to express their voice about victimisation, racism, and objectification of women. In this analysis, transnational feminism has influenced the strong Confucian South Korean society which holds the patriarchy believe in the social structure to rebel and stand for their rights as a woman (Herr, 2018).

\section{Methodology}

Qualitative method is applied to collect and analyse the primary data for this study. The research questions' theme and nature called for a closer, more detailed examination from the subjects' perspective and the effect of this phenomenon to the feminism ideology perspective. Phenomenology approach is used in this study as this study aims for depth and understanding of the women condition in South Korea, rather than statistical validity.

Primary sources like Korean films, Korean pop culture music and social media contents are used to analyse the main key themes and illustrate real-life examples of the issues of feminism arise due to the beauty standards culture in South Korea. Secondary sources like books and article journals, support the validity of the primary sources and the events.

\section{Analysis}

In this part, this study would answer the research questions stated earlier, which the first one is why women in South Korea need to reach the level of beauty standard? In South Korean, being pretty is a matter to get a better job. Almost everyone can get a good education in South Korea, and the opportunity to get a job is quite low as they have to compete with many people.

A chaebol is a family-owned industrial conglomerate. According to Seoul National University professor Sangin Park, the Korean economy depends on chaebol produced exports, such as steel, electronics, and cars produced by chaebols like Samsung, Hyundai, Lg and Lotte Group (Celina, 2018). People in Korea, especially fresh graduates, compete to get into these companies which promise a high salary. Unfortunate things happen to Korean females as 
most of the chaebol are male-dominated. As stated in The Statistic Portal in 2017, 72,587 male and 26,529 female employees worked for Samsung Electronics under permanent contracts at the headquarter in South Korea (Statista, 2018). As the job market gets competitive, some women applicants are going to extremes, such as undergoing plastic surgery to fulfill the beauty standard as a tool to attract the male employer to accept them because beauty is a kind of Curriculum Vitae (CV). Indeed, Korea is one of the few places where companies require photos on resumes so that the male-dominated company can choose better women's appearance. According to the Korean Job Portal, about 93 per cent of 760 companies in S. Korea required a photo for job applications.

The need for pretty women in the workplace can relate to South Korean's normal culture since in 19th century where according to Park and Kang (1994), women are like 'flowers of the office'. The words' flowers of the office' describe the perceived role of female staff in Korean companies. As 'flowers' they served to brighten up the otherwise, a masculine atmosphere of the office. For work, they were offered a limited range of tasks commanding low status and poor remuneration. For example, around 1980, women in the workplace are only allowed to do 'women's work' such as cleaning, decorating the office and making tea for male colleagues and visitors. The phrase insinuated that women were regarded as inferior, submissive and 'decorative' in other people's eyes, mostly men.

This study has taken the \#metoo campaign as a medium to describe the impact of this global campaign on South Korea's feminist movement in rebelling to the beauty standards to answer the second question: how transnational feminism influences Korea's feminist movement. Metoo was firstly started in the United States in 2006. The use of "Me Too" helped lift awareness of sexual assault and abuse in society (Joey, 2018). The phrase "Me Too" developed into a broader movement until the following years. When women begin to have freedom of expression regarding sexual abuse experience, it encourages other women to be brave to speak out of their persecuted experience. Therefore, the term 'me too' was highlighted because it uplifts other women to be together in this movement. As time passed, the MeToo movement has given impact not only for the sexual abuse cases but also for all marginalising women inequality rights cases.

Despite that, a young journalist from South Korea named Hawon Jung has written a book that told about the \#metoo movement in South Korea. It is inspired by the global feminism Me Too movement.
"Since 2018, so many women have asked me why South Korea remained so patriarchal despite its economic/technological advances, what propelled its \#metoo movement and how tech-based sexual abuse (ex. spycam porn) became so rampant in the country. I hope this book will be my answer to them." (Hawon, 2020)

\subsection{Oppression Movement}

Another resistance that feminists in South Korea developed inspired by the transnational feminism is Escape the Corset movement. Regarding objectifying women, South Korea has taken the \#MeToo movement as a guideline to together rebel the society's mindset. The demonstration named as "escape the corset" which, according to The New York Times (2018) was influenced by the \#MeToo global movement (Stevenson \& Alexandra,2018). This demonstration is an idea of the societal oppression of women that are bounded in a corset. Women have taken this movement to social media in a backlash against the unrealistic beauty standards requiring them to spend hours applying make-up and performing extensive skincare regimes, which notoriously involve ten steps or more. The movement, which first emerged on platforms such as Instagram and South Korea's, encourages people to look beyond the limited and conventional beauty standards demanded by society. Lina Bae (n.d.), a Korean YouTuber also joined this movement by saying;

"There are many women who wake up early in the morning and begin preparing their make-up one or two hours before going out, even though they do not want to."

Women supposedly have the freedom of not being judged including going makeup-free, wearing glasses instead of contact lenses, and wearing comfortable clothing and undergarment. Apart from that, some South Korea women have rallied by smashing their make-up compacts and lipsticks and posting pictures of it online accompanied by hashtags like \#feminist and \#MeToo.

\subsection{Support from Higher Authority}

"MeToo" campaign has gained President Moon Jae's attention and is willing to support that idea of feminism for his female citizens' sake. He stated in his speech on March that;

"with the Me Too movement, our society is in the midst of a crucial change, and this movement is leading Korea toward a society in which sexual equality and women's rights are realised, and the dignity of all people is respected". (President Moon Reiterates Support for 'Me Too' Movement, 2018).

Apart from that, he also uses his authority power in South Korea government to ban CV pictures for recruiting the workers. There were many cases where the employer wanted to only hire women with the criteria of beauty standards. 
He plans to implement the "blind hiring" strategy to recruit the employees in job fields that do not need to use physical requirements like modelling, cabin crews, or actresses. He believes that another job field except for those need skills and academic qualification is more than just appearance.

About 'blind hiring', it is not only South Korea that imposes these regulations on employers but it is also a concern in America where The Equal Employment Opportunity Commission advises employers against the request for candidates' pictures in the CV. However, it is not illegal on a federal level. However, questions about height and weight are also viewed as illegal according to federal law unless the question is relevant to the task or job.

\subsection{Breakage of Mainstream Beauty Image in Entertainment Industries}

Apart from that demonstration, \#MeToo has impacted the Korean entertainment industries to break the mindset of sticking to beauty standards' ideals. Kdrama and Kpop are very trending in Korea. Therefore, females' way to break the stereotype of beauty standards can be done by interpreting different beauty perspectives. For example, Kdrama entitles Weightlifting Fairy Kim Bok Joo whose dress unfashionable, quite chubby and muscular has successfully achieved her dream as a woman weightlifter with her family's support and friends. Even though she was lack of femininity, a famously handsome man is attracted to her personality despite her appearance.

Another example is Strong Woman Do Bong Soon. In this movie, her character is more outstanding from the male as she has stronger traits than the hero. She was born with a superpower, thus becoming the hero's bodyguard in this drama. Despite that, she did not also fulfil the Korean beauty standard criteria with suitable height and long legs. Some Kpop songs also have a secret message for the listeners that oppress the beauty standards in South Korea. One of them is Beautiful by Amber. Looking at the appearance of Amber, I bet everyone can read that Amber certainly does not follow the Korean beauty standard because she has short shaved hair and dressed like a man. In her song, what she is trying to convey was "being a woman is a burden", and the lyrics in the song that is very relatable with the feminism issues such as "Cause if I am happy I do not need, To change who I am now, I am just happy to be myself." It shows women are expected to act, dress, talk, and overall be a certain way society dictated a long time ago.

\section{Conclusion}

After all, transnational feminism which is \#MeToo has successfully impacted South Korea society's thoughts and mindset. Feminism is not very familiar yet in South Korea because of the strong conservational believe of Confucian they hold to which believe that a wife is "chip saram". It means that a wife is a person inside the house that will do all the households stuff and take care of the children only. It has shown its patriarchy side of the Confucian and women are not meant for the public affairs when they ought to stay at home. Women and men should stand on the same level and gain the same opportunity because women also have the right to shine her capabilities and skills as men do. Limited access to freedom will make women inferior and weak human beings, allowing anyone to violate her feelings and rights.

Therefore, transnational feminist had given the light for women in South Korea to oppress when they got other women at their back. Being feminist in South Korea is not easy when many cases involve women's abuse just because they are feminist. For example, two girls were attacked and beaten by four Korean men until her skull is seeable and coated in blood, just because they failed to embody the "ideal" Korean girls' standards. The reason each girl had was short haircuts, and therefore the men assumed they were feminists. It was sad to see that kind of situation happened just because they did not follow society's ideal beauty standard. Women are not an object that people can shape them equivalent to their interest. Let them grow in free and accept them for their natural existence. This study suggests to preserve the feminist value is through an employer should require women with qualified expertise or skill according to the job qualification rather than focusing on the physical appearance of women and teachers should educate and instil high self-esteem in young children so that they will believe that inner beauty is much more matter than the outside.

Besides that, the feminist voice needs to be more vocal and solid. The higher authority could notice the violation of female rights and influence women's protection in South Korea. Lastly, female leaders should represent Korean women in protecting their rights because the previous female president, Park Guen Hye does not resemble feminism due to conservative Confucian belief.

\section{Acknowledgement}

The authors would like to acknowledge the Centre for General Studies and Co-curricular, Universiti Tun Hussein Onn Malaysia, Johor and Department of International Relations, Universitas Indonesia, Depok, Indonesia.

\section{References}

Beauvoir, S. D. (2011). The works of Simone de Beauvoir: Includes: The ethics of ambiguity, 1947, the second sex, 1949, on the publication of The second sex, 1963 interview, Biography. United States: Createspace

Celina. "Personal and Managerial Capitalism: Evidence from ..." Accessed December 19, 2018. http://www.helsinki.fi/iehc2006/papers1/Kim.pdf. 
Elfving-Hwang, Joanna. (2013). Cosmetic Surgery and Embodying the Moral Self in South Korean Popular Makeover Culture. The Asia-Pacific Journal. 11

Galdi, Silvia. (2014). How far is objectification of women in television from sexual harassment? Psicologia Sociale. 9. 271-289. 10.1482/78350

Galezeau. "The body, cosmetics and aesthetics in South Korea. The emergence of a field of research ", article on deposit on HAL-SHS, identifier halshs-01211686

Hawon, J. [allyjung]. (2020, November 9). Since 2018, so many women have asked me why South Korea remained so patriarchal despite its economic/technological advances, what propelled its \#metoo movement and how tech-based sexual abuse (ex. spycam porn) became so rampant in the country. I hope this book will be my answer for them.

Retrieved

from https://twitter.com/allyjung/status/1325745367040872450

Herr, Ranjoo S. "Reclaiming Third World Feminism: Or Why Transnational Feminism Needs Third World Feminism." Academia.edu - Share Research. Accessed December 19, 2018

Joey. "Pamela Anderson Criticises the \#MeToo Movement: 'This Third Wave of Feminism Is a Bore'." Yahoo! News. November 06, 2018. Accessed December 19, 2018. https://www.yahoo.com/entertainment/pamela-anderson-criticizesmetoo-movement-164147524.html

NATE. "2 Women Violently Beaten Up By 4 Korean Men... Because of Their Hairstyle." Koreaboo. November 14, 2018. Accessed December 19, 2018. https://www.koreaboo.com/news/2-women-violently-beaten-4-korean-menhairstyle/

Park, Eun Chae. "SELLING SUCCESFUL BODIES." The Construction of Female Beauty Ideals on the Websites of Korean Cosmetic Surgery Clinics, July 13, 2018, 6-30

Rhee, Seung \& An, Soo-Jung \& Hwang, Rahil. (2017). Contemporary Koreans' Perceptions of Facial Beauty. Archives of Plastic Surgery. 44. 390-399. 10.5999/aps.2017.44.5.390

Statista. "South Korea: Samsung Electronics Employees by Gender and Type 2017 | Statistic." Statista. Accessed December 19, 2018. https://www.statista.com/statistics/682333/samsung-electronics-employees-number-by-genderand-type/

Stevenson, Alexandra. "South Korea Loves Plastic Surgery and Makeup. Some Women Want to Change That." The New York Times. November 23, 2018. Accessed December 18, 2018.

https://www.nytimes.com/2018/11/23/business/south-korea-makeup-plastic-surgery-free-the-corset.html.

Tay. "Marxism, Feminism and the Fight for Liberation." SocialistWorker.org. Accessed December $19,2018$. https://socialistworker.org/2013/07/10/marxism-feminism-and-womens-liberation.

Tong, R., \&amp; Botts, T. F. (2017). Feminist Thought. A More Comprehensive Introduction, (Westview Press), $173-$ 210

"The Ethics of Ambiguity," Philosophy Now: A Magazine of Ideas, accessed October 01, 2018, https://philosophynow.org/issues/69/The_Ethics_of_Ambiguity

"Why South Korea Is the Plastic Surgery Capital of the World." Business Insider. September 22, 2015. Accessed December 19, 2018. https://www.businessinsider.com/south-korea-is-the-plastic-surgery-capital-of-the-world-2015$9 / ? \mathrm{IR}=\mathrm{T}$

황장진. "President Moon Reiterates Support for 'Me Too' Movement." Yonhap News Agency. March 03, 2018. Accessed December 18, 2018. https://en.yna.co.kr/view/AEN20180304003800315 